\section{How to enhance scholarly impact: recommendations for university administrators, researchers and educators}

\author{
Herman Aguinis, Larry Yu and Cevat Tosun \\ Department of Management, The George Washington University School of Business, \\ Washington, District of Columbia, USA
}

\begin{abstract}
Purpose - The purpose of this study is to examine scholarly impact which is critical to universities in their aspiration to create, disseminate and apply knowledge. However, scholarly impact is an elusive concept. First, the authors present a conceptual model to clarify different dimensions of scholarly impact (i.e. theory and research, education, organizations and society) and four key stakeholders (i.e. other researchers, students, practitioners and policy makers). Second, the authors provide actionable recommendations for university administrators, researchers and educators on how to enhance impact. The scholarly impact model is flexible, expandable, scalable and adaptable to universities in different regions of the world and with different strategic priorities.

Design/methodology/approach - The authors conducted a general review of the literature and offered a multidimensional and multistakeholder model of scholarly impact to guide future actions aimed at enhancing scholarly impact.

Findings - The authors describe the multidimensional and multistakeholder nature of the critical and yet elusive concept of scholarly impact. The authors delineate multiple dimensions of impact, different stakeholders involved and recommendations for enhancing scholarly impact in the future.

Practical implications - The authors offer practical and actionable recommendations on how to enhance scholarly impact. For university administrators, the authors recommend aligning scholarly impact goals with actions and resource-allocation decisions; ensuring that performance management and reward systems are consistent with impact goals; being strategic in selecting a journal list; developing a strong doctoral program; and promoting practical knowledge and applications. For researchers and educators, the authors recommend developing a personal scholarly impact plan; becoming an academic decathlete; finding ways to affect multiple impact dimensions simultaneously; and leveraging social media to broaden impact on external stakeholders. Implementing these recommendations will benefit other researchers, students, practitioners (e.g. managers, consultants) and policy makers.
\end{abstract}

Originality/value - The authors provide an innovative way of conceptualizing scholarly impact. In turn, the conceptual analysis results in actionable recommendations for university administrators, researchers and educators to enhance impact.

Keywords Research impact, External stakeholders, Research practicality, Internal stakeholders

Paper type General review

(C) Herman Aguinis, Larry Yu and Cevat Tosun. Published by Emerald Publishing Limited. This article is published under the Creative Commons Attribution (CC BY 4.0) licence. Anyone may reproduce, distribute, translate and create derivative works of this article (for both commercial and non-commercial purposes), subject to full attribution to the original publication and authors. The full terms of this licence maybe seen at http://creativecommons.org/licences/by/4.0/legalcode

The authors thank Fevzi Okumus and three International Journal of Contemporary Hospitality Management anonymous reviewers for highly constructive feedback.
Enhancing scholarly impact

Received 15 October 2020 Revised 26 November 2020 Accepted 26 November 2020 
IJCHM

33,8

\section{Introduction}

Universities were founded for the purpose of creating, disseminating and applying knowledge. If they fulfill these lofty aspirations, we conclude that universities have scholarly impact: "a significant or major effect" (Merriam Webster Dictionary, 2020). At present, having an impact is not just an aspirational statement - it is something that is demanded by societies around the world (Buckley, 2019; Ryan, 2015).

Ironically, the meaning of scholarly impact is not entirely clear (Buckley, 2019). Universities maintain relationships with and aspire to have an impact on different types of stakeholders such as students, alumni, other scholars, business organizations, government, funding agencies and society at large. But, because of a lack of clear definition, initiatives aimed at increasing impact do not always attain the intended effect (Anderson et al., 2017; Penfield et al., 2014). Similarly, the scholarly impact of individual researchers and educators is not clearly defined. For example, although impact is usually described broadly, the literature on the impact of individual scholars has focused almost exclusively on how they have an effect on other scholars - as measured by citation-based metrics (Aguinis et al., 2012, 2020c; Dev et al., 2015; Okumus et al., 2019; Park et al., 2011).

Clearly, we are not the first ones to address the topic of scholarly impact. For example, using a knowledge management framework, Mody et al. (2018) identified institutional factors that serve as antecedents of a supportive culture and effective infrastructure for nurturing impactful researchers. Also, Chin and Law (2020) adopted a constructivist approach to identify research habits for impactful scholarship by interviewing a sample of 36 researchers in Hong Kong. In addition, Phillips et al. (2018) conducted a study to understand the impact of business issues on society from the perspective of practitioners, society and researchers.

The purpose of our article is to build upon existing research but go beyond by offering a solution to the challenge of clarifying the meaning of scholarly impact. Just as importantly, we provide recommendations on how to enhance impact. To do so, we first present a multistakeholder and multidimensional model of impact. Then, we provide actionable recommendations for university administrators as well as researchers and educators on how to enhance impact.

\section{Scholarly impact: a multidimensional and multistakeholder model}

Most researchers and educators in hospitality and tourism management, and many other fields, want to and even need to have an impact (Walsh, 2011). That is, we wish to have a significant or major effect on different types of stakeholders because making a difference is the reason why most professors choose an academic career (Walsh, 2011).

Figure 1 summarizes our multidimensional and multistakeholder model of scholarly impact. This figure shows that different dimensions of impact are directly associated with specific and unique stakeholders. For the theory and research dimension, the key stakeholders are other researchers and impact is usually measured using citations - the extent to which a scholar influences the thinking and work of other scholars. For the education dimension, the aspiration is to have a long-lasting influence on student development by disseminating relevant knowledge and its applications. For the organizations dimension, the aspiration is to have an influence on practitioners: managers and consultants who use the knowledge generated by research. Finally, for the society dimension, the goal is to have an influence on policy makers (e.g. legislators, government officials).

An important aspect of the conceptual model in Figure 1 is that scholarly impact on one of the dimensions is not necessarily associated with the impact on the others. For example, 


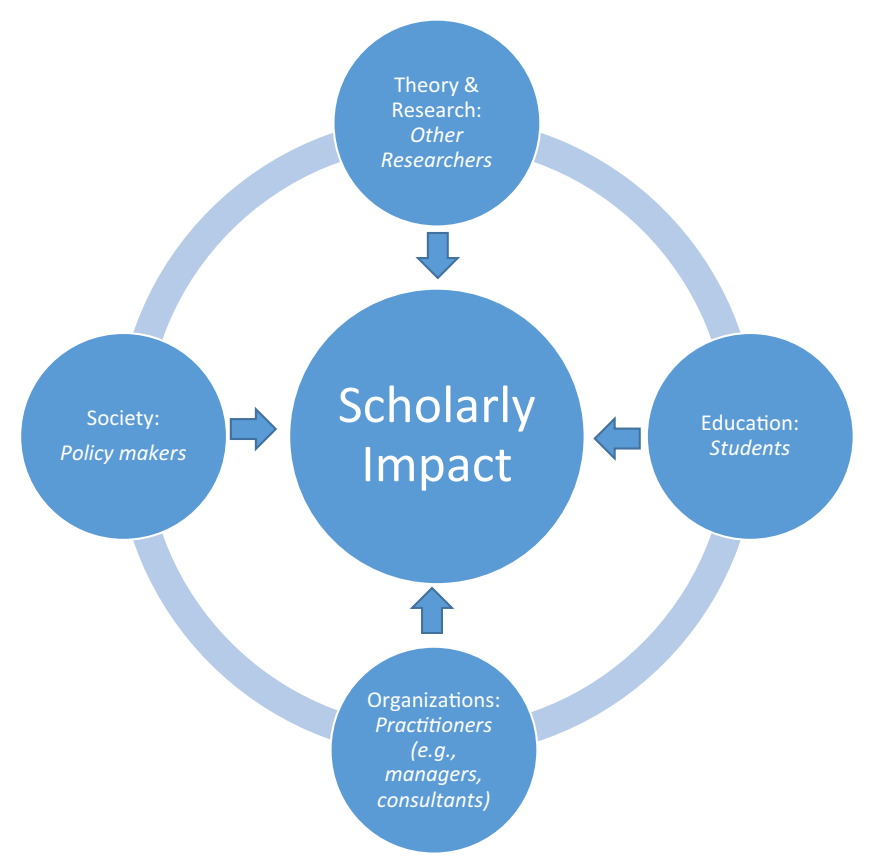

Enhancing scholarly impact

2487

Aguinis et al. (2012) found that citations (i.e. measure of impact on theory and research) explained less than $3 \%$ of the variance in the number of mentions in non-.edu Google pages (i.e. measure of impact on organizations and society). Therefore, the fact that a scholar has a high degree of influence on other scholars, based on her high citation count, does not necessarily mean that she has the same high degree of impact on other stakeholders including students, organizations and society.

The model in Figure 1 builds upon Aguinis et al.'s (2014) pluralist conceptualization of scholarly impact. Because it is multidimensional and multistakeholder, the model in Figure 1 makes it explicit that there is a need to:

- use different measures of impact depending on which dimension and stakeholder are the intended targets;

- be locally sensitive as institutions may have different strategic priorities over time regarding their targeted dimensions and stakeholders;

- understand that the impact dimensions can be complementary and should not be viewed as being mutually exclusive; and

- consider the possibility that certain actions may affect more than one dimension and type of stakeholder simultaneously.

As an illustration of the broad applicability of our model specifically in the hospitality and tourism field, consider two studies that examined the views of university program heads for evaluating faculty's impact (Law and Chon, 2007; Tung et al., 2018). Specifically, these studies revealed that there has been a clear shift in emphasis toward the theory and research dimension because many universities focus on publications in top-tier and social sciences citation index (SSCI)-indexed journals given their placement on rankings and impact 
IJCHM

33,8

\section{8}

indicators (e.g. average number of citations received by articles published in those journals). These studies also revealed the increasing value of having an impact on organizations (i.e. practitioners including managers and consultants) by highlighting the importance of, for example, organizing conferences for both researchers and practitioners. Regarding impact on education, there is also the expectation that faculty members will supervise doctoral and master's students and have a clear influence on their careers (Tung et al., 2018).

Our model also allows us to uncover possible shifts from certain dimensions and stakeholders (e.g. organizations/practitioners) to others (e.g. theory and research/other researchers) and make explicit which ones are given more or less importance (e.g. publications in top-tier journals are given more value than publications in journals targeting practitioners). Another advantage of our model is that it makes these choices, which sometimes may be implicit, explicit. In other words, the model allows us to understand a university's actions and resource-allocation decisions about impact by classifying them in terms of their targeted dimensions and stakeholders (e.g. more resources and rewards on the theory and research compared to the organizations dimension). Finally, the model is valuefree in the sense that it does not dictate which dimension and type of stakeholders that should be more relevant - but it allows us to quickly understand, based on observed actions and resource allocations, implicit underlying values about which dimensions and stakeholders are given more weight.

\section{Enhancing scholarly impact}

There are two key agents of scholarly impact. First, university administrators (e.g. department chairs, deans, research center directors, vice presidents for research) play a critical leadership role because they have decision-making authority over performance management and reward systems which influence faculty priorities and effort (Tracey, 2018). So, university administrators play a central role regarding which particular impact dimensions may be targeted for improvement. For example, as mentioned earlier, the latest survey of university program heads of hospitality and tourism mostly recognized the increased role of top tier SSCI-indexed journals as highly valued and impactful contributions (Tung et al., 2018).

Second, researchers and educators are the agents who generate impact through their research, teaching and service activities. Today's academic job market is hyper competitive, and universities are increasingly interested in hiring and promoting impactful faculty. In addition, regardless of extrinsic rewards associated with impact (e.g. salary increases, promotion, research and teaching support, summer support), most academics are intrinsically motivated to do impactful work (Aguinis et al., 2013).

What can university administrators and researchers and educators do to enhance scholarly impact? First, we offer recommendations for university administrators. As a preview, Table 1 includes a summary of recommendations together with implementation guidelines.

\subsection{Recommendations for university administrators}

3.1.1 Recommendation \#1: align scholarly impact goals with actions and resource-allocation decisions. University administrators need to make sure there is alignment among strategic impact priorities, actions and resource-allocation decisions. For example, if a university's strategic priority is to have a high impact on theory and research, actions may involve recruiting senior faculty with known research records to fill endowed chairs and professorships, engaging with external stakeholders to generate funds to be used for research, establishing formal mentoring programs for early-career faculty and providing 
Recommendations

1. Align scholarly impact goals with actions and resourceallocation decisions
Implementation guidelines

As an implementation example, if a university's strategic impact priority is theory and research, then

- Recruit senior faculty with known research records to fill endowed chairs and professorships

- Engage in external fundraising to support research

- Establish formal mentoring programs for early-career faculty

- Provide methodological training so researchers' skills are updated on an ongoing basis

- Provide clear guidelines to administrators of all levels on how to measure impact on theory and research (e.g. include an increase in endowed chairs and professorships through deans' fundraising efforts, research expenditure increase from both public and private funding sources, increased number of journal publications with desired visibility and impact as well as citation-based metrics)

2. Ensure that performance management and reward systems are consistent with impact goals

3. Be strategic in selecting a journal list

- Implement a portfolio approach to performance management because not all faculty members are typically able to influence all dimensions at a similarly high level

- Recognize that some faculty members may excel at one impact dimension whereas others may excel at another

- Allocate different weights to different dimensions of impact

- Adjust the weights over time as faculty member's interests and trajectory change

- Acknowledge and reward impact dimensions important to the university

- Reexamine the journal list to motivate faculty to engage in research that can not only affect other researchers but also other stakeholders - the education, organizations and society dimensions of impact

- Use a journal list as a management tool to measure performance and allocate rewards and thereby enhance impact but the selection of journals needs to be consistent with the type of impact a university desires

- In addition to theory and research, if the goal is to impact other dimensions, then include journals devoted to them such as those focusing on the scholarship of teaching (i.e. influencing the education dimension and students as stakeholders)

4. Develop a strong doctoral program

5. Promote practical knowledge and applications

- Consider that investing in the doctoral program is a long-term commitment critical for several impact dimensions because benefits include publications (i.e. theory and research dimension) but a reputation as well

- Provide teaching opportunities so doctoral students develop their pedagogical skills

- Mentor and train students to write practitioner-oriented articles and learn how to bridge theory and practice early in their training

- Train doctoral students to write practitioner-focused articles

- Consider developing a doctorate of practice program to affect the organizations and society dimensions of impact (e.g. Doctor of Hotel and Tourism Management at the School of Hotel and Tourism Management, Hong Kong Polytechnic University)

- Coordinate with the development office, career center and alumni office to formulate a strategy for bridging the gap between education and research with industry so faculty can have broader industry exposure
Enhancing scholarly impact

- Forge a partnership with local private organizations and public agencies to provide access to faculty and students for experiential learning and applied research

- Institutionalize faculty consulting practice that combines with experiential learning projects because student involvement in consulting projects also enhances impact on the education dimension

- Provide incentives for faculty to choose to spend part of their sabbaticals conducting applied research in an organization rather than another university
Table 1. Enhancing scholarly impact: recommendations for university administrators 
IJCHM

33,8

2490 methodological training so researchers' skills are updated on an ongoing basis. Given this particular illustration, and to ensure strategic alignment, this university would provide clear guidelines to administrators at all levels on how to measure impact on theory and research. These actions can include an increase in endowed chairs and professorships through deans' fundraising efforts, research expenditure increase from both public and private funding sources and increased number of journal articles with desired visibility and impact as well as citations and its variants (e.g. total citations, h-index - as measured by different databases including Clarivate Web of Science, Google Scholar and Scopus).

On the other hand, lack of strategic alignment between what are considered the most critical impact dimensions and actions and resource-allocation decisions creates confusion and unintended effects. To continue with this illustration, if this university aspires to have an impact on theory and research but does not offer necessary resources (e.g. reduced teaching loads for top researchers, summer support so faculty can allocate time to research), the most impactful research performers are likely to leave (Aguinis and O'Boyle, 2014).

In sum, the recommendation is not necessarily to invest resources in one dimension or another. Rather, the point is to make resource allocations in a way that they are directly related to a unit's or university's strategic priorities regarding impact.

3.1.2 Recommendation \#2: ensure that performance management and reward systems are consistent with impact goals. University administrators need to implement transparent performance management systems to incentivize faculty to focus on the targeted impact dimensions and stakeholders (Aguinis, 2019). University administrators are fully aware of the idiosyncratic talent of the faculty and should tap into their skills and talent accordingly given that not all faculty members are typically able to influence all dimensions at a similarly high level. Therefore, some faculty members may excel in the theory and research dimension - as demonstrated by their citations. On the other hand, others may excel at the society dimension - as demonstrated by their involvement in their role of an expert witness in a court case with implications for policymaking. Yet others may demonstrate their highest impact on education by, for example, writing a best-selling textbook or teaching case.

The recommendation is to implement a portfolio approach to performance management in which all of the impact dimensions important to the university are acknowledged and rewarded. In fact, our scholarly impact model in Figure 1 allows universities to allocate different weights to different dimensions of impact. Also, these weights can be adjusted over time as a faculty member's interests and career trajectory change. For example, if a faculty member is focused on theory and research and education equally, then his overall performance score may be weighted as $50 \%$ for each of these two impact dimensions. But, our model is flexible in that, for example, another faculty member may have a weight of $30 \%$ for theory and research and $70 \%$ for education. Such weight allocation can change across individuals and within an individual over time to consider that people's efforts and interests may change as they progress through the academic ranks. Accordingly, each faculty member's valuable contribution to the different dimensions of impact can be recognized and rewarded based on their skills and interests.

3.1.3 Recommendation \#3: be strategic in selecting a journal list. University administrators face increasing pressure from competitive institutions to hire and retain faculty who publish in "A-journals" (Aguinis et al., 2020b, 2020c). Journal lists define what is a top journal and what is not, and the number of articles published in those top journals usually affects university rankings (Aguinis et al., 2020b), such as the popular QS World University Rankings (Tung et al., 2018). Accordingly, it is not surprising that many university administrators push faculty to publish in those journals because that helps 
improve rankings. Similarly, it is also not surprising that deans and other university administrators view other scholarly activities such as writing books, book chapters and textbooks, as less important (Tung et al., 2018).

Aguinis et al. (2020b) provided a discussion of the advantages and disadvantages of relying on a journal list. Some of these advantages include the following points:

- setting standards for determining the value of research;

- showing transparency and fairness of performance assessment and reward systems;

- reducing possible bias held by researchers from other fields;

- protecting junior faculty from biased decisions; and

- establishing guidelines for doctoral student training and early career faculty development.

However, chiefly relying on the A-journals for judging research impact has the following disadvantages, which were also echoed by Law et al. (2019):

- generalizing negative effects on the field's research methods, knowledge generation and social dynamics;

- increasing use of questionable research practices (QRPs);

- motivating only counting the frequency of publications in A-journals without consideration for replication or contributions to a broader discourse engaging different stakeholders (e.g. managerial or policy implications);

- increasing of multiauthorship which leads to reciprocal systems of sham authorship and publication credit;

- a narrowing focus on the impact on other researchers exclusively;

- stifling innovative exploration for new phenomena and theorizing because of the preferred use of certain methodologies;

- discouraging researchers' communications with external stakeholders; and

- incentivizing faculty to focus primarily on immediately monetizable (e.g. A-publications associated with summer support) versus nonmonetizable activities (e.g. mentoring a struggling junior faculty member and institution building).

Realizing the positive and negative effects of using A-journals to evaluate faculty impact and determine rewards, university administrators need to reexamine their journal list to motivate faculty to engage in research that can influence other researchers and also other stakeholders - the education, organizations and society dimensions of impact. We recommend the use of a journal list as a management tool to measure performance and allocate rewards and thereby enhance impact. But, like any tool, there is a need to be strategic in how we use it. Specifically, the selection of journals needs to be consistent with the type of impact a university desires. For example, hospitality and tourism schools strive for teaching excellence by linking theory and practice in classroom instructions. Many faculty, therefore, conduct pedagogical research to advance the scholarship of teaching (e.g. the effectiveness of various instructional methods, student learning behaviors and online teaching and learning). Accordingly, if there is a desire to impact hospitality and tourism education (i.e. students as primary stakeholders), then journals devoted to pedagogical scholarship such as Journal of Hospitality and Tourism Education and Journal of Hospitality, Leisure, Sport and Tourism Education would be included on the list.
Enhancing scholarly impact 
IJCHM 33,8
3.1.4 Recommendation \#4: develop a strong doctoral program. University administrators face increasing pressure in managing doctoral programs because of budget constraints. The good news is that investing in a doctoral program is a long-term commitment critical for several impact dimensions. Benefits from the doctoral program are not just publications (i.e. theory and research dimension), but reputation as well. Schools with doctoral programs produce loyal alumni. These alumni become professors at other universities and spread the word about their alma mater, which eventually translates into good ratings that are based on reputation given that alumni ratings are influenced by the departments and programs they attended (Bedeian et al., 2010; Ryazanova and McNamara, 2016). Also, well-trained doctoral students eventually become leaders in the field (e.g. journal editors, officers in professional organizations and high-level administrators in their universities). All these outcomes contribute to the impact of the school in the education, organizations and society dimensions in addition to theory and research.

University administrators, therefore, need to take a long-term strategic view to fund and support the doctoral program. In addition to research activities, university administrators and faculty mentors need to provide teaching opportunities, so doctoral students develop their pedagogical skills. Furthermore, doctoral students should be mentored and trained to write practitioner-oriented articles and learn how to bridge theory and practice early in their training (Fisher, 2020). If they do so, they will have the inclination to broaden their scholarly impact from the beginning of their careers.

Finally, university administrators could also consider developing a doctorate of practice program (Banerjee and Morley, 2013). Such a program can be extremely beneficial in terms of external impact because alumni from this program are influential practitioner-scholars in organizations. There are several such programs around the world and one of them is the Doctor of Hotel and Tourism Management offered by the School of Hotel and Tourism Management at the Hong Kong Polytechnic University.

3.1.5 Recommendation \#5: promote practical knowledge and applications. Finally, to enhance the impact on organizations and society, university administrators should promote a better integration of hospitality and tourism education and research with industry practice. Though hospitality and tourism education has come a long way in establishing itself as a reputable academic field, similar to the field of management (Cascio and Aguinis, 2008), there is a gap between hospitality and tourism education and research in relation to industry needs (Walters et al., 2015). These research-education and research-practice gaps are even wider in developing countries.

There are two challenges that administrators must address in terms of promoting practical knowledge and applications that will result in enhanced impact regarding the organizations and society dimensions. First, many hospitality and tourism schools recruit professors of practice. But, because practical industry skills are usually not as highly valued compared to publications in top journals, those individuals with practical skills face an entry barrier to pursue an academic career path. Another challenge is the lack of opportunities for faculty to engage in practical industry experience such as consulting activities.

University administrators should coordinate with the development office, career center and alumni office to formulate a strategy for bridging the research-education and researchpractice gaps, so faculty can have broader industry exposure. For example, one possibility is to forge a partnership with local private organizations and public agencies to provide access to faculty and students for experiential learning and applied research. Related to this point, university administrators can institutionalize faculty consulting practice that combines with experiential learning projects. The reason is that student involvement in consulting projects will also enhance the impact on the education dimension. Finally, administrators can 
provide incentives for faculty to choose to spend part of their sabbaticals conducting applied research in an organization rather than another university. This would also help faculty enhance their impact on the organizations dimension.

\subsection{Recommendations for researchers and educators}

As a preview of this section, Table 2 includes a summary of recommendations and implementation guidelines.

3.2.1 Recommendation \#1: develop your personal scholarly impact plan. A critical question all of us faculty members, as well as aspiring faculty members, need to ask is: What is my personal scholarly impact plan for the near term (1-2 years), mid-range (3-6years) and longer term (6+ years)? When do I want to have an impact on which of the dimensions and stakeholders, and how exactly am I going to do so?

\begin{tabular}{ll}
\hline Recommendations & Implementation guidelines \\
\hline 1. Develop your personal & - Ask yourself the following questions: \\
scholarly impact plan & - What is my personal scholarly impact plan for the near term (1-2 years), \\
mid-range (3-6 years) and longer term (6+ years)? \\
- When do I want to have an impact on which of the dimensions and \\
stakeholders, and how exactly am I going to do so? \\
- Receive top-notch research training which is indispensable for producing \\
high-quality and valid research that is trustworthy and credible \\
- Be mindful that impact begins with minimizing questionable research \\
practices and sharpening your skills to keep abreast with the theorizing \\
and methodological requirements for high-impact research
\end{tabular}

2. Become an academic decathlete

- It is not sufficient to have a high impact on just one dimension

- Aspire to become an academic decathlete, though it is not necessary to excel in all of the impact dimensions, but at least some of them

- Before tenure, a faculty member may focus on high-impact theory and research and education but impact priorities may change over time

- As an inspiring exemplar, consider the case of academic decathlete Professor Tom Lee (University of Washington)

3. Find ways to affect

- Start with rigorous and high-quality research

\section{Enhancing scholarly impact}

2493 multiple impact dimensions simultaneously

- Do not wait until tenure to consider the impact on dimensions other than theory and research because it may be then too late to adjust one's impact mindset

- Write bridging articles targeting students and practitioners

- Write a textbook integrating academic and applied sources

- Write cases for instructional use that influence other academics, students and external stakeholders

- As inspiring exemplars, consider the cases of Professor Emeritus Joe Goldblatt (Queen Margaret University), Professor Michael Hitt (Texas A\&M University) and Professor Susan Jackson (Rutgers University)

4. Leverage social media to broaden impact on external stakeholders
- Move beyond interactions only limited to other researchers and educators involving listservs, e-newsletters, e-journals and annual conferences

- Leverage new channels to share your expertise via LinkedIn, Twitter and Facebook

- As an inspiring exemplar, consider the case of Professor Jeffrey Pfeffer (Stanford University)
Table 2.

Enhancing scholarly impact: recommendations for researchers and educators 
IJCHM 33,8
Before answering these questions, the first step, which is particularly critical for doctoral students and junior scholars, is to receive top-notch research training which is indispensable for producing high-quality and valid research (Aguinis et al., 2020a). Clearly, trustworthy and credible research is more likely to have an impact on theory and research. In addition, however, it will obviously be very difficult to have an impact on any of the four dimensions through untrustworthy and irreproducible scholarship.

Given the tremendous pressure to publish in prestigious journals (i.e. theory and research dimension), it is not surprising that QRPs are found in many different aspects of research practices dealing with data, hypotheses reporting, model construction and statistical reporting (Aguinis et al., 2020a; Tourish and Craig, 2020; Murphy and Aguinis, 2019). Therefore, researchers need to be mindful that impact begins with minimizing QRPs and sharpening their skills to keep abreast with the theorizing and methodological requirements for high-impact research.

3.2.2 Recommendation \#2: become an academic decathlete. Faculty face higher and higher expectations to excel in multiple roles as educators and researchers - as well as roles outside of the university walls. Thus, we have reached a point at which faculty are expected to become "academic decathletes" (Kovoor-Misra, 2012). Just like decathletes must excel in different events (e.g. long jump, javelin throw, $100 \mathrm{~m}$ ), it is not sufficient for faculty to have high impact on just one dimension. Accordingly, faculty take on different roles and responsibilities including teaching different types of students (e.g. undergraduate, graduate, doctoral, executive), engaging in both academic research and applied research, taking on administrative roles at the university, becoming members of journal editorial boards and also associate editors or editor of journals and also engaging in consulting practice.

Can we do it all? Clearly, to become an academic decathlete seems to be a daunting aspiration for all faculty and particularly for early career ones. However, we believe this is the strategic direction faculty should consider, though this does not involve necessarily excelling in all dimensions, but at least some of them (Kovoor-Misra, 2012). For example, before tenure, a faculty member may focus on high-impact theory and research and education. Then, impact priorities may change over time. Later in the career, one can select other stakeholders as the main targets of impact (e.g. practitioners). At that time, other highimpact activities can include a leadership role in the university and the academy, becoming a journal editorial board member (and eventually associate editor and editor), focusing on executive education, continuing on research excellence both in academic and practicefocused publications and devoting time to consulting activities to disseminate knowledge to external stakeholders.

There are many exemplary academic decathletes. We would like to highlight Professor Tom Lee, as featured in the case study by Kovoor-Misra (2012). Professor Tom Lee (Thomas William Lee) holds the Hughes M. Blake Endowed Professor of Management at the Michael G. Foster School of Business at University of Washington. Professor Lee served as the school's Associate Dean for Academic and Faculty Affairs. He held several leadership positions in academic associations, including serving as President of the Academy of Management and Editor of the Academy of Management Journal. He taught undergraduate, MBA and Executive MBA students and mentored over 30 doctoral students. He is a fellow of the Academy of Management and the Society for Industrial and Organizational Psychology (Kovoor-Misra, 2012, p. 280). As of the writing of our article, his research has received more than 24,000 Google Scholar citations and his h-index is 51 (i.e. 51 of his publications have received at least 51 citations each). This example of an academic decathlete illustrates the multiple dimensions of a high-impact scholar who has had an important influence on a broad range of stakeholders. 
3.2.3 Recommendation \#3: find ways to affect multiple impact dimensions simultaneously. Our scholarly impact model suggests that the multiple dimensions are not mutually exclusive. In fact, we recommend for faculty to find ways to affect more than one impact dimension simultaneously. First, faculty should start with rigorous and high-quality research. This is the first step in the process in which faculty can establish a visible research identity and build a network of colleagues and collaborators. But, faculty should not wait until tenure to consider activities that influence dimensions other than theory and research because it may be then too late to adjust one's impact mindset.

Fisher (2020) made a compelling argument that faculty should write practitioner-oriented articles targeting students and practitioners. Writing bridging papers is a natural off-shoot of more traditional scholarly articles and results in three benefits: making research relevant, making a difference and improving our teaching because students enjoy reading their professors' practical articles (Fisher, 2020, pp. 417-418).

On a related note, another synergistic activity is to write a textbook as a way to influence students (Aguinis et al., 2019). A textbook integrates academic and applied sources and offers students balanced science-practice knowledge for their education. A well-researched and structured textbook will make a long-lasting impact on the students after they become practitioners. As an inspiring exemplar, Professor Emeritus Joe Goldblatt (Queen Margaret University), one of the pioneering educators in event management, authored, coauthored and edited 39 books. His first book on special event management, Special Events: The Art and Science of Celebration, in its eighth edition (co-authored now with Seungwon Lee) has been translated into Korean, Chinese, Japanese, Bulgarian and Spanish. This book is also referenced by researchers and used by practitioners for training and development. This illustrates Professor Goldblatt's impact on the particular domain of event management education, research and practice and across multiple stakeholders.

Writing cases for instructional use is another way of influencing several dimensions simultaneously. The annual listing of the most popular case studies, compiled by the Yale School of Management Case Research and Development Team based on sales, publishing data, Google analytics and adoption information, provides insights into the multiple stakeholders positively influenced. Based on a database of over 300,000 users in 161 countries, two-thirds of the case adoptions came from outside of the USA (Yale School of Management, 2020). Case studies allow faculty to describe the critical challenges faced by organizations and also influence faculty and students in terms of their teaching and learning. Specifically, in hospitality and tourism, the recently launched Journal of Hospitality and Tourism Cases is devoted to cases.

Examining and analyzing a sample of top management scholars for scholarly impact, Aguinis and colleagues (2012) implemented a novel approach for measuring impact on external stakeholders: the number of Google indexed, non-edu web pages. We mentioned earlier that this study found a trivial association between Web of Science citations and non-.edu Google web page mentions. But, interestingly, this study also uncovered exemplars of scholars who have had a high impact on both internal and external stakeholders. For example, Professor Michael Hitt at Texas A\&M University was ranked 16th regarding citations and ranked 9th based on 1,454,925 non-.edu Google indexed pages. Another example is Professor Susan Jackson at Rutgers University, ranked 33rd in citation counts and 10th in non-.edu Google indexed pages of 1,205,200. These two examples demonstrate the high degree and broad influence some scholars have had regarding multiple dimensions of impact and set inspiring examples for all of us to emulate.
Enhancing scholarly impact

2495 
IJCHM

33,8

3.2.4 Recommendation \#4 leverage social media to broaden impact on external stakeholders. Researchers and educators use listservs, e-newsletters, e-journals and attend annual conferences to disseminate research outcomes and teaching practices - all interactions that involve primarily internal, other researchers and educators. These are effective strategies for engaging other researchers. But, social media enables researchers and educators to interact with and impact a broader and global audience (Dauenhauer, 2020). For example, many faculty share their expertise via LinkedIn, Twitter and Facebook. As an inspiring exemplar, Professor Jeffrey Pfeffer (Stanford University) is an active user of social media and regularly shares his research, videos of keynote addresses and evidencebased analyses of current events. His effective use of social media platforms and active engagement in communities has attracted large followings of scholars and practitioners alike on Twitter $(12,600)$ and LinkedIn $(80,000)$. Clearly, the effective use of social media can increase the reach and influence of research, especially on external stakeholders.

\section{Conclusions}

The scholarly impact is a sort of Holy Grail for universities, university administrators and researchers and educators worldwide: Everyone is looking for it because of its miraculous powers that provide happiness in infinite abundance. The following mission statements illustrate how the impact is indeed a global aspiration:

[The mission of the] University of Oxford is to provide world-class research and education. We will do this in ways which benefit society on a local, regional, national and global scale (University of Oxford, 2018).

Yale is committed to improving the world today and for future generations through outstanding research and scholarship, education, preservation, and practice (Yale University, 2020).

Peking University hopes to provide scholarly contributions to society, cultivate capable and inventive young minds, and ultimately better Chinese society both internally and on the global front (Peking University, 2020).

However, there is a lack of clarity about the meaning of the elusive concept of scholarly impact. Just like the Holy Grail, everyone wants it, but we do not really know what it is, and we do not really know how to get it. Accordingly, we offered a scholarly impact model based on the recognition that there are multiple scholarly impact dimensions and different types of stakeholders influenced by each (Figure 1). We also offered actionable recommendations that university administrators (Table 1) and researchers and educators (Table 2) can implement to enhance scholarly impact.

We are well aware of different research, academic, teaching, administrative, cultural and political conditions in different countries. Priorities regarding scholarly impact vary within countries, universities and individual faculty and also within countries, universities and individual faculty over time. This is why our model is flexible, expandable, scalable and adaptable to universities and individuals in different regions of the world and with different strategic personal and institutional priorities. Thus, the model can be equally as useful for, for example, a comprehensive research university and a teaching-oriented university. The flexibility of the model allows for the addition of more or even alternative dimensions and stakeholders as appropriate. For example, if a university is interested primarily in having an impact on a specific industry, our model can be easily expanded to include another circle and accommodate this new impact dimension. Overall, we hope our model and recommendations will result in more rewarding and extrinsically and intrinsically satisfying scholarship - scholarship that matters to both internal and external stakeholders. 


\section{References}

Aguinis, H. (2019), Performance Management for Dummies, Wiley, Hoboken, NJ.

Aguinis, H. and O’Boyle, E. (2014), "Star performers in twenty-first century organizations", Personnel Psychology, Vol. 67 No. 2, pp. 313-350, doi: 10.1111/peps.12054.

Enhancing scholarly impact

Aguinis, H., Joo, H. and Gottfredson, R.K. (2013), "What monetary rewards can and cannot do: how to show employees the money", Business Horizons, Vol. 56 No. 2, pp. 241-249, doi: 10.1016/j. bushor.2012.11.007.

Aguinis, H., Banks, G.C., Rogelberg, S.G. and Cascio, W.F. (2020a), “Actionable recommendations for narrowing the science-practice gap in open science", Organizational Behavior and Human Decision Processes, Vol. 158, pp. 27-35, doi: 10.1016/j.obhdp.2020.02.007.

Aguinis, H., Cummings, C., Ramani, R.S. and Cummings, T.G. (2020b), "An a is an A: the new bottom line for valuing academic research", Academy of Management Perspectives, Vol. 34 No. 1, pp. 135-154, doi: 10.5465/amp.2017.0193.

Aguinis, H., Cummings, C., Ramani, R.S. and Cummings, T.G. (2020c), "An a is an A: the new bottom line for valuing academic research", Academy of Management Perspectives, Vol. 34 No. 1, pp. 170-172, doi: 10.5465/amp.2019.0110.

Aguinis, H., Shapiro, D.L., Antonacopoulou, E.P. and Cummings, T.G. (2014), "Scholarly impact: a pluralist conceptualization", Academy of Management Learning and Education, Vol. 13 No. 4, pp. 623-639, doi: 10.5465/amle.2014.0121.

Aguinis, H., Suárez-González, I., Lannelongue, G. and Joo, H. (2012), "Scholarly impact revisited", Academy of Management Perspectives, Vol. 26 No. 2, pp. 105-132, doi: 10.5465/amp.2011.0088.

Aguinis, H., Ramani, R.S., Alabduljader, N., Bailey, J.R. and Lee, J. (2019), "A pluralist conceptualization of scholarly impact in management education: students as stakeholders", Academy of Management Learning and Education, Vol. 18 No. 1, pp. 11-42, doi:10.5465/amle.2017.0488.

Anderson, L., Ellwood, P. and Coleman, C. (2017), "The impactful academic: relational management education as an intervention for impact", British Journal of Management, Vol. 28 No. 1, pp. 14-28, doi: 10.1111/1467-8551.12202.

Banerjee, S. and Morley, C. (2013), "Professional doctorates in management: toward a practice-based approach to doctoral education”, Academy of Management Learning and Education, Vol. 12 No. 2, pp. 173-193, doi: 10.5465/amle.2012.0159.

Bedeian, A.G., Cavazos, D.E., Hunt, J.G. and Jauch, L.R. (2010), "Doctoral degree prestige and the academic marketplace: a study of career mobility within the management discipline", Academy of Management Learning and Education, Vol. 9 No. 1, pp. 11-25, doi: 10.5465/amle.9.1.zqr11.

Buckley, R. (2019), "Tourism publications as newly tradeable commodities: academic performance, prestige, power, competition, constrains and consents", Annals of Tourism Research, Vol. 74, pp. 121-133, doi: 10.1016/j.annals.2018.11.004.

Cascio, W.F. and Aguinis, H. (2008), "Research in industrial and organizational psychology from 1963 to 2007: changes, choices, and trends", Journal of Applied Psychology, Vol. 93 No. 5, pp. 1062-1081, doi: 10.1037/0021-9010.93.5.1062.

Chin, D.C.W. and Law, R. (2020), "Back to basics: academic research in tourism and hospitality management - the case of Hong Kong", Tourism and Hospitality Research, Vol. 20 No. 3, pp. 379-383, doi: 10.1177/1467358419863157.

Dauenhauer, P.J. (2020), "Expand your academic impact with social media best practices", Matter, Vol. 2 No. 4, pp. 789-793, doi: doi:10.1016/j.matt.2020.02.017.

Dev, C.S., Parsa, H.G., Parsa, R.A. and Bujisic, M. (2015), “Assessing faculty productivity by research impact: introducing Dp2 index", Journal of Teaching in Travel and Tourism, Vol. 15 No. 2, pp. 93-124, doi: 10.1080/15313220.2015.1026471.

Fisher, G. (2020), "Why every business professor should write practitioner-focused articles", Business Horizons, Vol. 63 No. 4, pp. 417-419, doi: 10.1016/j.bushor.2020.03.004. 
IJCHM 33,8

Kovoor-Misra, S. (2012), “Academic decathletes: insights from the metaphor and an exemplar”, Journal of Management Inquiry, Vol. 21 No. 3, pp. 279-286, doi: 10.1177/1056492611428749.

Law, R. and Chon, K. (2007), "Evaluating research performance in tourism and hospitality: the perspective of university program heads", Tourism Management, Vol. 28 No. 5, pp. 1203-1211, doi: 10.1016/j.tourman.2006.09.022.

Law, R., Chan, I.C.C. and Zhao, X. (2019), "Ranking hospitality and tourism journals", Journal of Hospitality and Tourism Research, Vol. 43 No. 5, pp. 754-761, doi:10.1177/1096348019828028.

Merriam Webster Dictionary (2020), "Impact", available at: Merriam Webster Dictionary, 2020 (accessed 12 September 2020).

Mody, M., Tang, C., Gaulke, C. and Gordon, S. (2018), "Examining the personal and institutional determinants of research productivity in hospitality and tourism management", Journal of Hospitality and Tourism Education, Vol. 30 No. 1, pp. 36-51, doi: 10.1080/10963758.2017.1413378.

Murphy, K.R. and Aguinis, H. (2019), "HARKing: how badly can cherry picking and question trolling produce bias in published results?”, Journal of Business and Psychology, Vol. 34 No. 1, pp. 1-17.

Okumus, F., Köseoglu, M.A., Putra, E.D., Dogan, I.C. and Yildiz, M. (2019), “A bibliometric analysis of lodging-context research from 1990 to 2016", Journal of Hospitality and Tourism Research, Vol. 43 No. 2, pp. 210-225, doi: 10.1177/1096348018765321.

Park, K., Phillips, W.J., Canter, D.D. and Abbott, J. (2011), "Hospitality and tourism research rankings by author, university, and country using six major journals: the first decade of the new millennium", Journal of Hospitality and Tourism Research, Vol. 35 No. 3, pp. 381-416, doi: $10.1177 / 1096348011400743$.

Peking University (2020), "Mission statement”, available at: https://roundranking.com/universities/ peking-university.html?sort=O\&year=2020\&subject=SO (accessed 3 October 2020).

Penfield, T., Baker, M.J., Scoble, R. and Wykes, M.C. (2014), "Assessment, evaluations, and definitions of research impact: a review”, Research Evaluation, Vol. 23 No. 1, pp. 21-32, doi: 10.1093/reseval/rvt021.

Phillips, P., Moutinho, L. and Godinho, P. (2018), "Developing and testing a method to measure academic societal impact”, Higher Education Quarterly, Vol. 72 No. 2, pp. 121-140, doi: 10.1111/ hequ.12154.

Ryan, C. (2015), "Trends in hospitality management research: a personal reflection", International Journal of Contemporary Hospitality Management, Vol. 27 No. 3, pp. 340-361, doi: 10.1108/ IJCHM-12-2013-0544.

Ryazanova, O. and McNamara, P. (2016), "Socialization and proactive behavior: multilevel exploration of research productivity drivers in US business schools", Academy of Management Learning and Education, Vol. 15 No. 3, pp. 525-548, doi: 10.5465/amle.2015.0084.

Tourish, D. and Craig, R. (2020), "Research misconduct in business and management studies: causes, consequences, and possible remedies", Journal of Management Inquiry, Vol. 29 No. 2, pp. 174-187, doi: 10.1177/1056492618792621.

Tracey, J.B. (2018), “Moving the impact dial”, Cornell Hospitality Quarterly, Vol. 59 No. 3, p. 200, doi: $10.1177 / 1938965518784676$.

Tung, V.W.S., Law, R. and Chon, K. (2018), "Changing proxies for evaluating research performance: what matters to university program heads?", Tourism Recreation Research, Vol. 43 No. 3, pp. 346-355, doi: 10.1080/02508281.2017.1415654.

University of Oxford (2018), “Strategic plan 2018-2023", available at: www.ox.ac.uk/about/ organisation/strategic-plan-2018-23 (accessed 3 October 2020).

Walsh, J.P. (2011), "2010 Presidential address: embracing the sacred in our secular scholarly world”, Academy of Management Review, Vol. 36 No. 2, pp. 215-234, doi: 10.5465/amr.36.2.zok215.

Walters, G., Burns, P. and Stettler, J. (2015), "Fostering collaboration between academia and the tourism sector", Tourism Planning and Development, Vol. 12 No. 4, pp. 489-494, doi: 10.1080/21568316.2015.1076596. 
Yale School of Management (2020), “Top 40 most popular case studies of 2019”, available at: https:// som.yale.edu/news/2020/02/top-40-most-popular-case-studies-of-2019 (accessed 9 October 2020).

Yale University (2020), "Mission statement", available at: www.yale.edu/about-yale/mission-statement (accessed 3 October 2020).

Enhancing scholarly impact

\begin{abstract}
About the authors
Herman Aguinis is Avram Tucker Distinguished Scholar, Professor of Management and Chairperson of the Department of Management at The George Washington University School of Business. His research addresses the global acquisition and deployment of talent in organizations and research methods and analysis. His professional and life agenda is to have an impact on the academic community and society at large. He has published more than 170 journal articles and 9 books, and Clarivate Analytics/Web of Science ranked him among the world's 100 most impactful researchers in Economics and Business in 2020, 2019 and 2018. He is currently serving as the President-Elect of the Academy of Management. Herman Aguinis is the corresponding author and can be contacted at: haguinis@gwu.edu

Larry $\mathrm{Yu}$ is Professor of Hospitality Management in the Department of Management at The George Washington University School of Business. His teaching and research interests focus on organizational, strategic and global aspects of tourism and hospitality business, particularly on leadership, management innovation, employee creativity and human capital development. He consults with government agencies, international aid organizations and business organizations in Asia and the Middle East.

Cevat Tosun is Eisenhower Chair and Professor of Tourism Studies and Management, and Director of Master of Tourism Administration Program at the Department of Management, The George Washington University School of Business. He has served as a business development consultant for top international consulting companies in Europe. His research interests include tourism impacts, sustainable tourism development, tourism policy and planning, community participation, destination development and destination marketing.
\end{abstract}

For instructions on how to order reprints of this article, please visit our website: www.emeraldgrouppublishing.com/licensing/reprints.htm Or contact us for further details: permissions@emeraldinsight.com 